Full length article

\title{
Orange peel + nanostructured zero-valent-iron composite for the removal of hexavalent chromium in water
}

\author{
O. Olea-Mejía ${ }^{\mathrm{a}, *}$, A. Cabral-Prieto ${ }^{\mathrm{b}}$, U. Salcedo-Castillo $^{\mathrm{a}}$, G. López-Tellez ${ }^{\mathrm{a}}$, \\ O. Olea-Cardoso ${ }^{c}$, R. López-Castañares ${ }^{c}$ \\ a Universidad Autónoma del Estado de México, Centro Conjunto de Investigación en Química Sustentable CCIQS UAEM-UNAM, Carr Toluca-Atlacomulco km \\ 14.5, Toluca, Estado de México, CP 50200, Mexico \\ ${ }^{\mathrm{b}}$ Instituto Nacional de Investigaciones Nucleares, Departamento de Física, Apdo, Postal 18-1027, México D.F., Mexico \\ c Universidad Autónoma del Estado de México, Facultad de Química, Tollocan esq. Colon s/n. Toluca, Estado de México, CP 50120, Mexico
}

\section{A R T I C L E I N F O}

\section{Article history:}

Received 28 September 2016

Received in revised form 15 June 2017

Accepted 16 June 2017

\section{Keywords:}

Pulsed plasma in liquids

Iron nanostructures

Chromium removal

Mössbauer spectroscopy

\begin{abstract}
A B S T R A C T
In this work we used the Pulsed Plasma in Liquid technique to synthesize zero-valent iron nanostructures. We used a DC Power Source to produce such plasma on water and methanol. The obtained particles were characterized by TEM to determine their shape and size and Mossbauer Spectroscopy to investigate the chemical state of the iron present. We found that $80 \%$ of the particles produced in water are composed of metallic iron and when methanol is used $97 \%$ of the particles are metallic iron. Once the Fe colloid was formed, orange skin was impregnated with these nanostructures for the removal of in water solution. $\mathrm{The} \mathrm{Cr}(\mathrm{VI})$ removal experiments were done in a batch system in the presence of the composites at an inicial concentration of $50 \mathrm{ppm}$ of $\mathrm{Cr}(\mathrm{VI})$. When using the iron nanostructures supported on the orange peel, the percentage of removal is $100 \%$ in the case of nanostructures formed in water and $96 \%$ when obtained in methanol.
\end{abstract}

(ㄷ) 2017 Elsevier B.V. All rights reserved.

\section{Introduction}

Hexavalent chromium $(\mathrm{Cr}(\mathrm{VI}))$ species are a serious environmental problem since they are known to be toxic, mutagenic and carcinogenic. Furthermore, the treatment of these species in water is difficult since they do not form insoluble precipitates at any $\mathrm{pH}$ value. There are two main processes to deal with this problem: the first one is to adsorb the $\mathrm{Cr}(\mathrm{VI})$ ions in a material and then, such material is removed from the water; the second one is to reduce $\mathrm{Cr}$ (VI) to $\mathrm{Cr}(\mathrm{III})$. The ionic species of $\mathrm{Cr}$ (III) have a significantly lower toxicity than those of $\mathrm{Cr}(\mathrm{VI})$ and are capable of forming insoluble compounds easily removed by precipitation. Therefore, the reduction method is preferred. There are a number of well-known chemical and electrochemical methods to achieve the reduction of $\mathrm{Cr}(\mathrm{VI})$ that have been in use for a long time [1].

Recently, iron oxide has been used to eliminate $\mathrm{Cr}(\mathrm{VI})$ by adsorption [2-5]. Also, Zero Valent Iron (ZVI) nanostructures are used to reduce $\mathrm{Cr}(\mathrm{VI})$ to $\mathrm{Cr}(\mathrm{III})$. This nanostructures are usually employed protected with a covering stabilizer or supported on a different material that can be easily removed by filtration or precipitation

\footnotetext{
* Corresponding author.

E-mail address: oleaoscar@yahoo.com.mx (O. Olea-Mejía).
}

[6-10]. Among the different methods to obtain metallic nanoparticles, Pulsed Plasma in Liquids (PPL) has emerged as a convenient low-cost technique that produce nanostructures without the formation of byproducts. Also, the nanostructures surface is free from any covering molecule, thus it can interact freely in chemical reactions, sorption processes, etc. [11-15]

Therefore, in this work we have used PPL to produce pure and uncovered ZVI nanostructures. Then, we have supported them on orange peel to produce a composite. Such new material has been used in the removal of $\mathrm{Cr}(\mathrm{VI})$ in water solution. Orange peel is an environment friendly natural material that is a waste after the orange juice has been extracted. Orange peel has been already used successfully by our group in previous works showing its adsorption/reduction capabilities [16,17].

\section{Materials and methods}

\subsection{Iron nanostructures synthesis and characterization}

Iron rods (99\% of purity) with approximate dimensions of $5 \times 5 \times 20 \mathrm{~mm}$ were used as the moving electrodes during the iron nanostructures production by PPL. The two liquid media used were distilled water and reagent grade methanol (Sigma-Aldrich). A commercial DC Power Source was used at $30 \mathrm{~V}$. The PPL experi- 

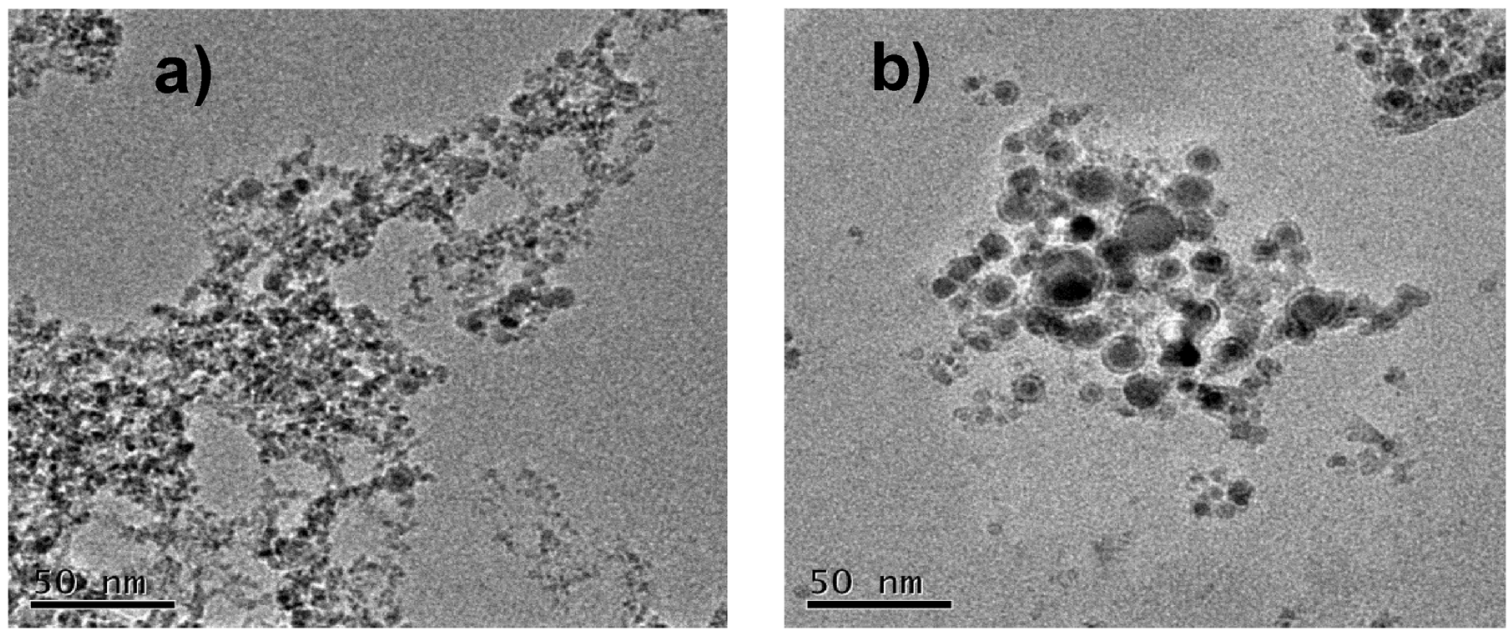

Fig. 1. TEM images of a) Fe nanostructures formed in water and b) Fe nanostructures formed in methanol.

ments were performed during two different intervals of time, the first one was done during $10 \mathrm{~min}$ to prepare the composites, and the second one during $1 \mathrm{~h}$ to obtain enough material $(\sim 50 \mathrm{mg})$ to perform Mössbauer measurements. The mass of the nanoparticles was estimated by weighting the Fe electrodes before and after the PPL experiments. To study the morphology and size of the nanostructures Transmission Electron Microscopy (TEM) was performed. One drop of the Iron colloids was placed on a carbon coated TEM grid (SPI Supplies) and left it to dry at room temperature. To be able to study the obtained Fe nanoparticles by Mössbauer Spectroscopy (MS), $\sim 50 \mathrm{mg}$ of Iron nanostructures were transferred from the liquid medium (water or ethanol) to a commercial epoxy resin precursor to avoid oxidation in air. After that, the resin containing the nanoparticles was chemically cured. The encapsulated Fe nanostructures were then studied by MS in a Wissel spectrometer operating in the constant acceleration mode and using a ${ }^{57} \mathrm{Co} / \mathrm{Rh}$. The reported isomer shifts are referred to metallic iron.

\subsection{Orange peel + iron nanostructures composite preparation and characterization}

Orange peel (Citrus Cinencis 'Valencia') was dried during one day at $80^{\circ} \mathrm{C}$ and milled to obtain a dry powder. Afterwards, it was mixed with the iron nanostructures colloid and left the mixture stirring during $3 \mathrm{~h}$. After that, the composite was allowed to sink to the bottom of the flask and then separated by decantation. In all cases we prepared $0.4 \mathrm{~g}$ ( $5 \%$ wt. of Fe) of composite. A small amount of the composite was placed in a Scanning Electron Microscopy (SEM) sample holder and left to dry at room temperature.

\subsection{Chromium removal}

The Chromium solution was prepared from $\mathrm{K}_{2} \mathrm{Cr}_{2} \mathrm{O}_{7}$ (SigmaAldrich, 99\% purity) at a concentration of $50 \mathrm{ppm}$ with respect to $\mathrm{Cr}$. The wet composites $(0.4 \mathrm{~g}, 5 \mathrm{wt} . \%$ of Fe $)$ were immediately mixed with $10 \mathrm{~mL}$ of the $\mathrm{Cr}(\mathrm{VI})$ solution during one hour at room temperature under magnetic stirring and a $\mathrm{pH}$ of 3 . After that, the composite was left to sink during $1 \mathrm{~min}$ and $200 \mu \mathrm{L}$ of the remaining solution were taken for the $\mathrm{Cr}(\mathrm{VI})$ concentration determination. Such determination was done using the dyphenilcarbazide colorimetric method already explained in previous works [16,17]. Shortly, a solution of dyphenilcarbazide at $\mathrm{pH} 3$ forms a pink complex with $\mathrm{Cr}(\mathrm{VI})$, which is spectroscopically analyzed at $542 \mathrm{~nm}$ using a UV Vis spectrophotometer.

\subsection{XPS characterization of the composites}

For the X-ray Photoelectron Spectroscopy (XPS) measurements, a small amount of composite was placed in a piece of carbon tape and introduced to the spectrometer. XPS wide and narrow spectra were acquired using a JEOL JPS-9200, equipped with a Mg X-ray source $(1253.6 \mathrm{eV})$ at $300 \mathrm{~W}$, the area of analysis was $3 \mathrm{~mm}^{2}$, and the vacuum around $7.5 \times 10^{-9}$ Torr for all samples. The spectra were analyzed using the Specsurf ${ }^{\mathrm{TM}}$ software included with the instrument. All spectra were charge corrected with respect to the adventitious carbon signal (C1s) at $284.5 \mathrm{eV}$. The Shirley method was used for the background subtraction, while for the curve fitting we used the Gauss-Lorentz method.

\section{Results and discussion}

\subsection{Iron nanostructures characterization}

Fig. 1 shows the TEM images of Fe nanostructures prepared by PPL in distilled water and methanol. When using water, small particles are formed that agglomerate forming bigger "networklike" structures as seen on Fig. 2a. Since no stabilizer was used, the formed particles tend to agglomerate rapidly forming such structures. On the other hand, when methanol is used the formation of bigger spherical particles is observed as well as the network structure (Fig. 2b). Clearly, the liquid media plays an important role on the size and shape of the nanostructures formation. According to Chen et al. [13], methanol may be capable of partially stabilize the formed nanoparticles and this could be the reason we see individual spherical nanoparticles when using this liquid.

To determine the oxidation state of the Fe atoms on our samples Mössbauer Spectroscopy was used. On Fig. 2 we show that the majority of our samples are composed of $\mathrm{Fe}^{0}$. In the case of water, $80.34 \%$ of the iron is in the metallic iron and the rest is for Fe ions (15.19\% and $4.47 \%$ for $\mathrm{Fe}^{+3}$ and $\mathrm{Fe}^{+2}$ respectively). As for methanol, only $2 \%$ is $\mathrm{Fe}^{+3}$ ions; the rest is composed of $7.5 \% \mathrm{ZVI}$ in nanometric sizes (less than $\sim 10 \mathrm{~nm}$ ) and $89.5 \%$ bigger forms. Therefore, the liquid medium not only affects the shape and form of the obtained nanostructures but their composition as well. In water, oxidation is expected to happen, however, as evidenced by Mössbauer Spectroscopy such oxidation is not complete and $80 \%$ of the Fe atoms remain in the metallic state. On the other hand, when using methanol as the liquid medium, the obtained nanoparticles are composed of $98 \% \mathrm{Fe}^{0}$. This could be due to the possible "stabilization" from methanol mentioned earlier. As discussed later, $\mathrm{Fe}^{0}$ 


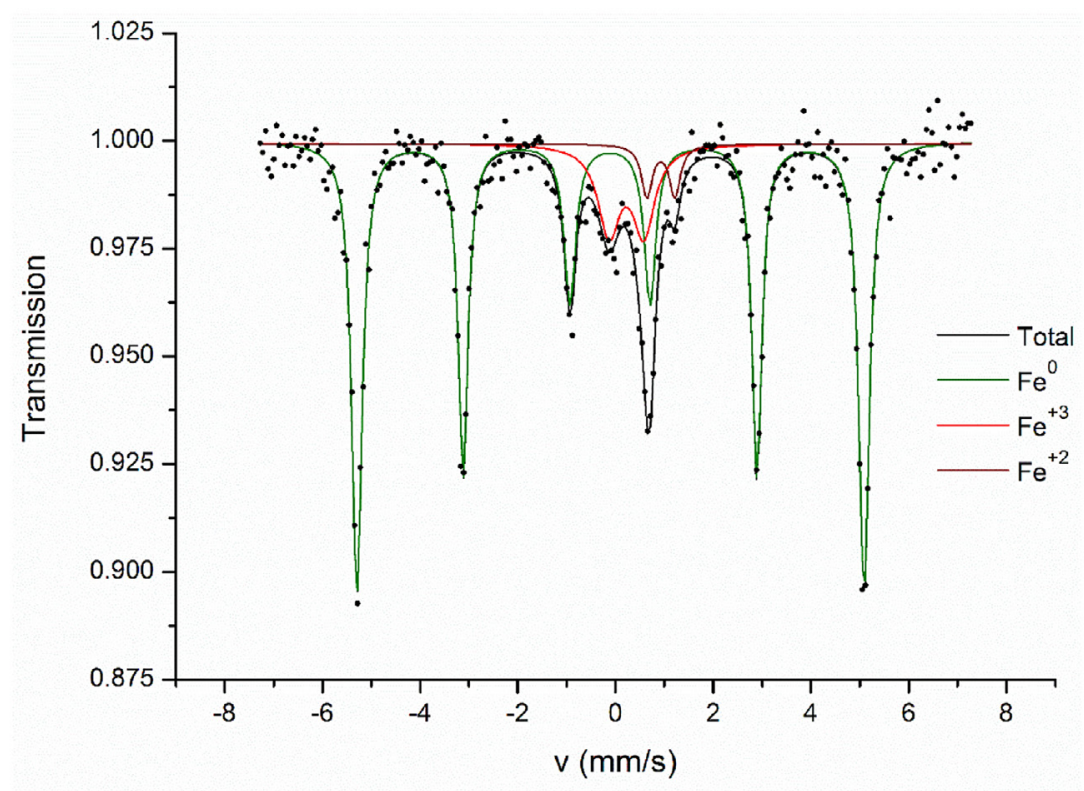

(a)

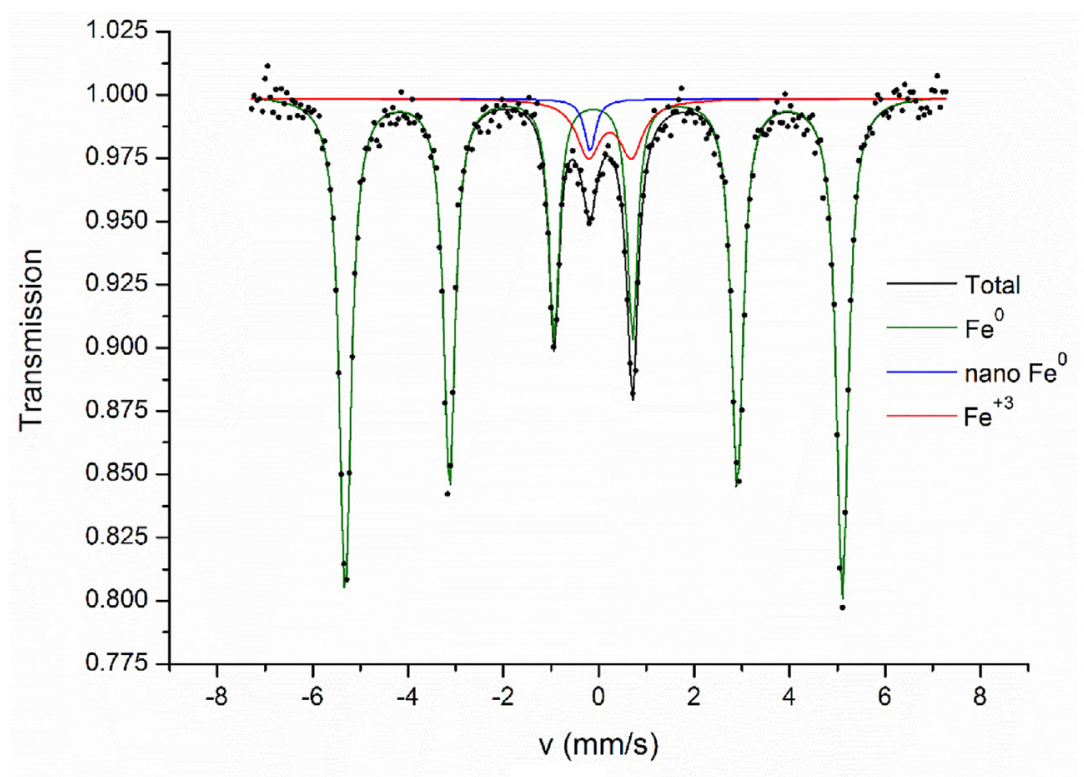

(b)

Fig. 2. Experimental Mössbauer spectra of iron species as produced by the PPL process in water (a) and methanol (b).

particles are preferred because of their higher capability to reduce $\mathrm{Cr}(\mathrm{VI})$ and the election of methanol as the synthesis medium seems obvious. However, water is still a good choice, because of cost, toxicity and safety.

\subsection{Orange peel + iron nanostructures characterization and $\mathrm{Cr}(\mathrm{VI})$ removal}

We determined the $\mathrm{Cr}(\mathrm{VI})$ concentration decrease from an initial solution ( $50 \mathrm{ppm}$ ) by UV-vis spectroscopy and the results are shown in Fig. 3. As seen, orange peel can remove by itself a considerable amount of $\mathrm{Cr}(\mathrm{VI})$ from the solution, around $60 \%$ of the initial concentration. According to the literature $[18,19]$, the point of zero charge (PZC) of the orange peel is between 4.2 and 4.5 of pH. Below this point, the surface of the material will be positively charged due to the $\mathrm{H}^{+}$ions. In our case, since the removal process was done at $\mathrm{pH}$ of 3 , the surface of the composite is positively charge. On the other hand, at this $\mathrm{pH}$ value, $\mathrm{Cr}(\mathrm{VI})$ exist predominantly in the form of $\mathrm{HCrO}_{4}{ }^{-}$; therefore, adsorption can occur via electrostatic interactions. Furthermore, it has been shown that orange peel can reduce $\mathrm{Cr}(\mathrm{VI})$ to $\mathrm{Cr}(\mathrm{III})$ under acidic conditions [17]. Therefore, this material can act as an adsorption material as well as a reducing one.

On the other hand, when using Fe nanostructures in the composite, the final $\mathrm{Cr}(\mathrm{VI})$ removal is as high as $100 \%$ when water is used in the PPL experiments and 96\% in the case of methanol (also shown in Fig. 3). Evidently, the use of iron allows to drastically decrease the concentration of $\mathrm{Cr}(\mathrm{VI})$ in solution. Adsorption and reduction of $\mathrm{Cr}(\mathrm{VI})$ can also happen due to the Fe species present in the compos- 


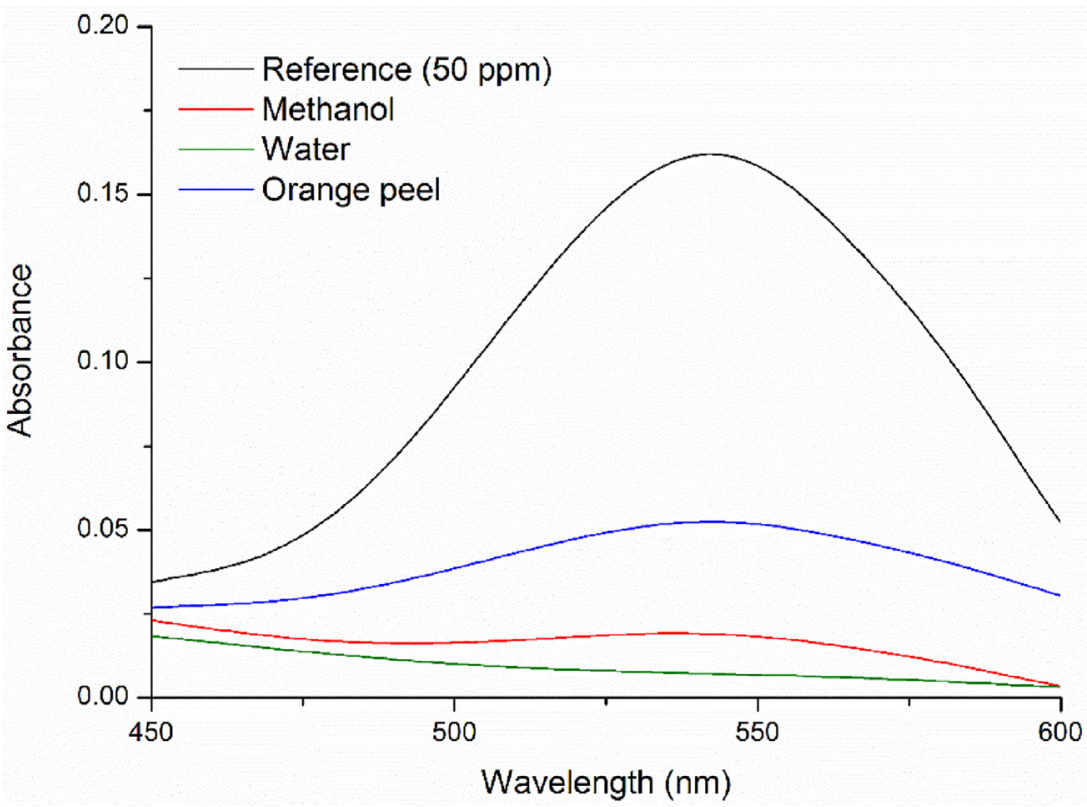

Fig. 3. UV-vis spectra of $\mathrm{Cr}(\mathrm{VI})$ solutions before and after treatment with pure orange peel and the orange peel + iron composites.

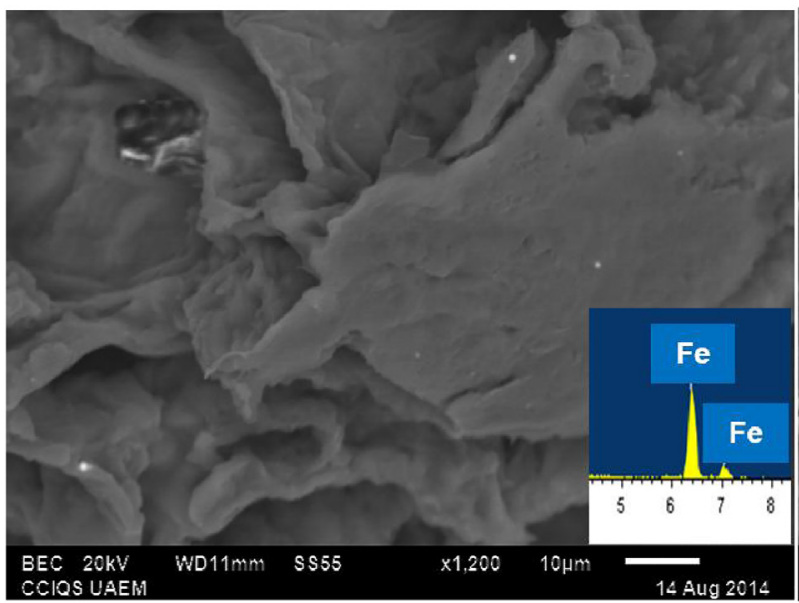

(a)

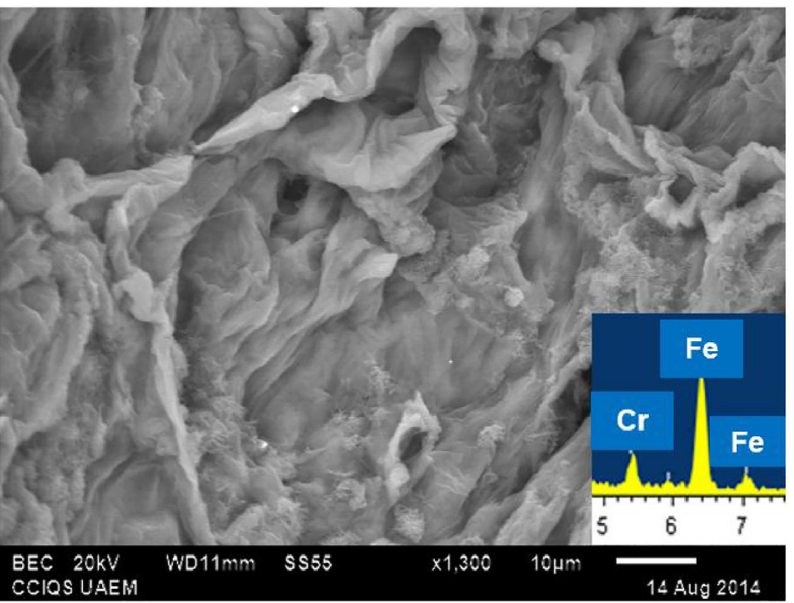

(b)

Fig. 4. SEM images and EDS of The orange peel + iron nanostructures before (a) and after the contact with the $\mathrm{Cr}(\mathrm{VI})$ solution (b).

ite; however, the mechanisms are more complex. $\mathrm{Fe}^{0}$ and $\mathrm{Fe}^{+2}$ can reduce $\mathrm{Cr}(\mathrm{VI})$ to $\mathrm{Cr}(\mathrm{III})$ as proved by Liu et al. [20], where it is suggested that such reduction starts by the instantaneous adsorption of $\mathrm{Cr}(\mathrm{VI})$ on Fe surface where the electron transfer takes place. As shown earlier, the synthesized nanoparticles are composed mainly of $\mathrm{Fe}^{0}$, but when introduced to acidic conditions $(\mathrm{pH} \sim 3)$ in water solution these particles can be rapidly oxidized to $\mathrm{Fe}^{+2}$ and/or $\mathrm{Fe}^{+3}$. Therefore, direct contact between $\mathrm{Cr}(\mathrm{VI})$ with $\mathrm{Fe}^{0}$ is unlikely to happen. However, as mentioned by Geng et al. and Scott et al. [21] the removal of $\mathrm{Cr}(\mathrm{VI})$ takes place in two steps: The first one is a rapid adsorption of $\mathrm{Cr}(\mathrm{VI})$ on the Fe species followed by the reduction to $\mathrm{Cr}$ (III) due to the $\mathrm{Fe}^{+2}$ left in the system. Overall, the two materials in the composite (orange peel and Fe nanostructures) can adsorb and reduce the $\mathrm{Cr}(\mathrm{VI})$ ions and the final removal will be the sum of the individual components.

The surface morphology of the composites was studied by SEM as shown in Fig. 4. Fig. 4a shows the surface of the composite before exposure to the $\mathrm{Cr}(\mathrm{VI})$ solution with the corresponding EDS spectrum. As we can see, the presence of Fe on the surface is evident, but the particles are not seen due to the resolution limit of the SEM.
On the other hand, Fig. 4b shows the composite surface after the $\mathrm{Cr}(\mathrm{VI})$ removal experiment with the corresponding EDS spectrum showing the elements of interest. Now, the signal from $\mathrm{Cr}$ appears in the spectrum, which means that $\mathrm{Cr}$ atoms have been adsorbed on the composite surface.

XPS was performed to prove the reduction of $\mathrm{Cr}(\mathrm{VI})$ solutions proposed earlier. In Fig. 5a we show the spectrum corresponding to the region of $\mathrm{Cr} 2 \mathrm{p}_{3 / 2}$. As mentioned, $\mathrm{Cr}(\mathrm{VI})$ ions can be either adsorbed or reduced on the composite surface, this is evidenced by the 2 deconvoluted peaks corresponding to $\mathrm{Cr}(\mathrm{III})$ and $\mathrm{Cr}(\mathrm{VI})$. It should be noted that the intensity of the peak related to $\mathrm{Cr}(\mathrm{III})$ is about $80 \%$ of the total intensity $(\mathrm{Cr}(\mathrm{VI})+\mathrm{Cr}(\mathrm{III}))$, proving an efficient reduction of $\mathrm{Cr}(\mathrm{VI})$ atoms. The remaining $\mathrm{Cr}(\mathrm{VI})$ ions are only adsorbed on the composite surface. The remaining $20 \%$ of $\mathrm{Cr}(\mathrm{VI})$ could be attributed to the $\mathrm{Cr}_{2} \mathrm{O}_{7}-2$ ion which may either need more time or more $\mathrm{Fe}^{+2}$ to undergo reduction. Fig. $5 \mathrm{~b}$, shows the XPS spectrum of the composite after contact with Chromium solution in the $2 \mathrm{p}_{3 / 2}$ Fe region. 2 peaks can be distinguished, one for $\mathrm{Fe}^{+2}$, with $76 \%$ of the total area and the other for $\mathrm{Fe}^{+3}$. As expected no peak related to metallic iron was found, which means that all of the $\mathrm{Fe}^{0}$ formed 




(a)

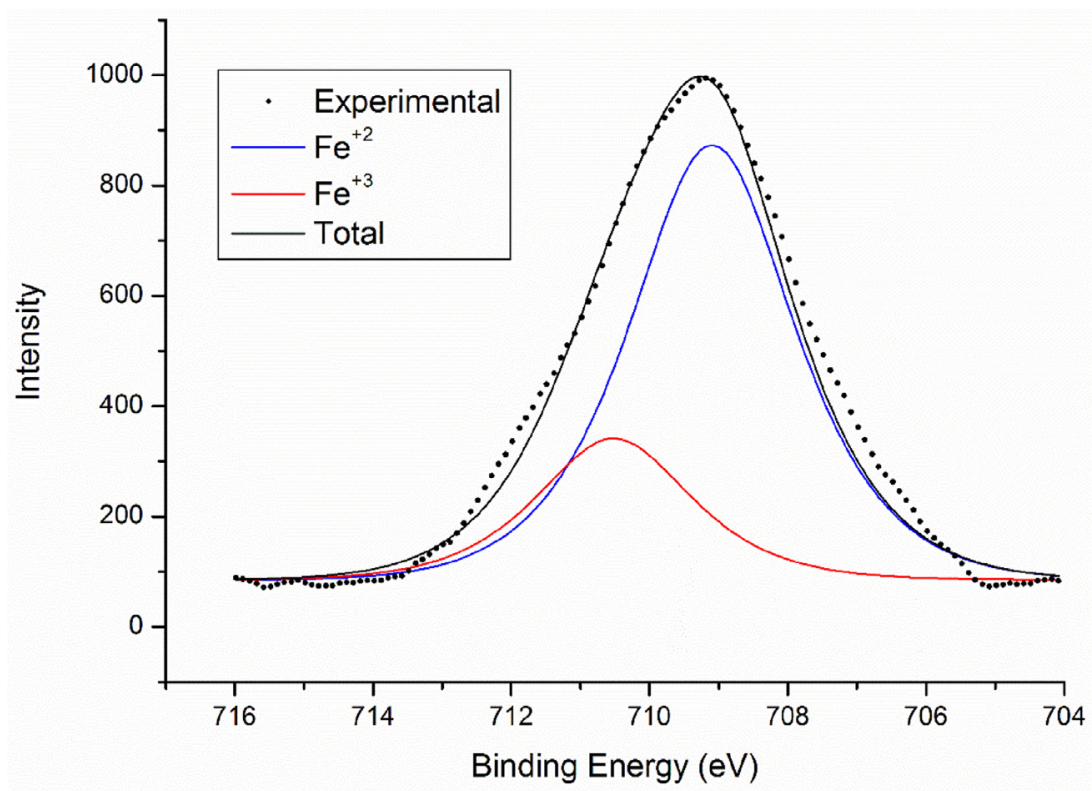

(b)

Fig. 5. High resolution XPS spectra of the orange peel + Fe composites after chromium removal experiments for (a) Cr and (b) Fe.

during the PPL experiments has undergone oxidation. However, it should be noted also that there is still a considerable amount of $\mathrm{Fe}^{+2}$ which could oxidize further to $\mathrm{Fe}^{+3}$, reducing more $\mathrm{Cr}(\mathrm{VI})$ to $\mathrm{Cr}$ (III) given enough time.

The maximum removal percentage reported in our previous work is $50 \%$ (from a $20 \mathrm{ppm} \mathrm{Cr}(\mathrm{VI})$ solution) during $1 \mathrm{~h}$ for a composite of orange peel with iron oxide nanorods [17]. In comparison, in this present work we achieved a removal percentage of $100 \%$ from a $50 \mathrm{ppm} \mathrm{Cr}(\mathrm{VI})$ solution. This difference is attributed to two main factors, namely the metallic state of the ZVI nanostructures and the absence of by-products when using PPL to synthesize such nanostructures.

\section{Conclusions}

We have successfully synthesized iron nanostructures by the PPL method using water and methanol as liquid media. Each liquid yields different shapes and sizes of nanostructures. The majority of the iron contained in our samples is in the metallic state with only a small portion of oxidized $\mathrm{Fe}^{+2}$ and $\mathrm{Fe}^{+3}$ as found with Mössbauer Spectroscopy. The Fe nanostructures were supported on orange peel to remove $\mathrm{Cr}(\mathrm{VI})$ contained in water in a batch system. The percentage of removal was $60 \%$ when pure orange peel was used, $100 \%$ when we used Fe nanostructures obtained in water and $96 \%$ in the case of methanol. As evidenced by XPS, $\mathrm{Cr}(\mathrm{VI})$ ions are reduced by the Fe species on the composite. Also, the surface of the composite can adsorb $\mathrm{Cr}$ ions. Therefore, the total removal mechanism 
is the sum of adsorption and reduction of the $\mathrm{Cr}(\mathrm{VI})$ ions happening on the composite surface.

\section{References}

[1] C.E. Barrera-Díaz, V. Lugo-Lugo, B. Bilyeu, A review of chemicalelectrochemical and biological methods for aqueous $\mathrm{Cr}(\mathrm{VI})$ reduction, J. Hazard. Mater. 223-224 (2012) 1-12.

[2] T.M. Abdel-Fattah, M.E. Mahmoud, M.M. Osmam, S.B. Ahmed, Magnetically active biosorbent for chromium species removal from aqueous media, J. Environ. Sci. Health - Part A Toxic/Hazard. Subst. Environ. Eng. 49 (2014) 1064-1076.

[3] T. Burks, M. Avila, F. Akhtar, M. Göthelid, P.C. Lansåker, M.S. Toprak, M. Muhammed, A. Uheida, Studies on the adsorption of chromium(VI) onto 3-Mercaptopropionic acid coated superparamagnetic iron oxide nanoparticles, J. Colloid Interface Sci. 425 (2014) 36-43.

[4] A. Rao, A. Bankar, A.R. Kumar, S. Gosavi, S. Zinjarde, Removal of hexavalent chromium ions by Yarrowia lipolytica cells modified with phyto-inspired Fe0/Fe304 nanoparticles, J. Contam. Hydrol. 146 (2013) 63-73.

[5] F. Zhang, J. Lan, Z. Zhao, Y. Yang, R. Tan, W. Song, Removal of heavy metal ions from aqueous solution using Fe3O4-SiO2-poly(1,2-diaminobenzene) core-shell sub-micron particles, J. Colloid Interface Sci. 387 (2012) 205-212.

[6] S. Bairoliya, S. Dubey, S. Bagchi, R. Rajasekaran, K. Ramanathan, V. Shanthi, Study on reduction of hexavalent chromium in aqueous solution using GT-Fe0 nanoparticles, J. Chem. Pharm. Res. 5 (2013) 123-129.

[7] B. Geng, Z. Jin, T. Li, X. Oi, Preparation of chitosan-stabilized Fe0 nanoparticles for removal of hexavalent chromium in water, Sci. Total Environ. 407 (2009) 4994-5000.

[8] P. Huang, Z. Ye, W. Xie, Q. Chen, J. Li, Z. Xu, M. Yao, Rapid magnetic removal of aqueous heavy metals and their relevant mechanisms using nanoscale zero valent iron (nZVI) particles, Water Res. 47 (2013) 4050-4058.

[9] Y. Li, T. Li, Z. Jin, Stabilization of Fe 0 nanoparticles with silica fume for enhanced transport and remediation of hexavalent chromium in water and soil, J. Environ. Sci. 23 (2011) 1211-1218.

[10] Q. Wang, H. Qian, Y. Yang, Z. Zhang, C. Naman, X. Xu, Reduction of hexavalent chromium by carboxymethyl cellulose-stabilized zero-valent iron nanoparticles, J. Contam. Hydrol. 114 (2010) 35-42.
[11] Z. Abdullaeva, E. Omurzak, C. Iwamoto, H.S. Ganapathy, S. Sulaimankulova, C. Liliang, T. Mashimo, Onion-like carbon-encapsulated Co, Ni, and Fe magnetic nanoparticles with low cytotoxicity synthesized by a pulsed plasma in a liquid, Carbon 50 (2012) 1776-1785.

[12] Z. Abdullaeva, E. Omurzak, C. Iwamoto, H. Ihara, H.S. Ganapathy, S Sulaimankulova, M. Koinuma, T. Mashimo, Pulsed plasma synthesis of iron and nickel nanoparticles coated by carbon for medical applications, Jpn. J. Appl. Phys. 52 (2013).

[13] L. Chen, T. Mashimo, C. Iwamoto, H. Okudera, E. Omurzak, H.S. Ganapathy, H. Ihara, J. Zhang, Z. Abdullaeva, S. Takebe, A. Yoshiasa, Synthesis of novel CoCx@C nanoparticles, Nanotechnology 24 (2013).

[14] L.L. Chen, E. Omurzak, S. Takebe, C. Iwamoto, T. Mashimo, Graphitic carbon-coated ZrC- and Co-nanoparticles synthesized by pulsed plasma in liquid, Adv. Mat. Res. (2011) 1978-1982.

[15] E. Omurzak, T. Mashimo, S. Sulaimankulova, S. Takebe, L. Chen, Z. Abdullaeva, C. Iwamoto, Y. Oishi, H. Ihara, H. Okudera, A. Yoshiasa, Wurtzite-type ZnS nanoparticles by pulsed electric discharge, Nanotechnology 22 (2011).

[16] G. López-Téllez, P. Balderas-Hernández, C.E. Barrera-Díaz, A.R. Vilchis-Nestor, G. Roa-Morales, B. Bilyeu, Green method to form iron oxide nanorods in orange peels for chromium(VI) reduction, J. Nanosci. Nanotechnol. 13 (2013) 2354-2361.

[17] G. López-Téllez, C.E. Barrera-Díaz, P. Balderas-Hernández, G. Roa-Morales, B. Bilyeu, Removal of hexavalent chromium in aquatic solutions by iron nanoparticles embedded in orange peel pith, Chem. Eng. J. 173 (2011) 480-485.

[18] J.V.T.M. De Souza, K.M. Diniz, C.L. Massocatto, C.R.T. Tarley, J. Caetano, D.C. Dragunski, Removal of $\mathrm{Pb}(\mathrm{II})$ form aqueous solution with orange sub-products chemically modified as biosorbent, BioResources 7 (2012) 2300-2318.

[19] L.A. Romero-Cano, L.V. Gonzalez-Gutierrez, L.A. Baldenegro-Perez, M.I Medina-Montes, Preparation of orange peels by instant controlled pressure drop and chemical modification for its use as biosorbent of organic pollutants, Rev. Mex. de Ing. Quim. 15 (2016) 481-491.

[20] T. Liu, D.C.W. Tsang, I.M.C. Lo, Chromium(VI) reduction kinetics by zero-valent iron in moderately hard water with humic acid: iron dissolution and humic acid adsorption, Environ. Sci. Technol. 42 (2008) 2092-2098.

[21] T.B. Scott, I.C. Popescu, R.A. Crane, C. Noubactep, Nano-scale metallic iron for the treatment of solutions containing multiple inorganic contaminants, J. Hazard. Mater. 186 (2011) 280-287. 